\title{
Iron mineral control on soil organic carbon cycling during permafrost thaw
}

\author{
EVA VOGGENREITER ${ }^{1}$, MONIQUE SÉZANNE \\ PATZNER $^{2}$, PRACHI JOSHI ${ }^{3}$, THOMAS BORCH ${ }^{4}$, CASEY \\ BRYCE $^{5}$ AND ANDREAS KAPPLER ${ }^{1}$
}

${ }^{1}$ Eberhard-Karls-University Tuebingen

${ }^{2}$ University of Tuebingen

${ }^{3}$ University of Tübingen

${ }^{4}$ Colorado State University

${ }^{5}$ University of Bristol

Presenting Author: eva.voggenreiter@uni-tuebingen.de

A large portion of the Earth's carbon stock is stored in permafrost soils. Increasing air temperatures will lead to thaw of permafrost which could contribute significantly to the carbon climate feedback. However, the extent to which soil mineralogy may control the emission of greenhouse gases is poorly understood. For instance, ferric iron (Fe(III)) minerals are known for their high sorption capacity of organic carbon, thus lowering its bioavailability and decreasing the biomineralization of organic matter to $\mathrm{CO}_{2}$ and $\mathrm{CH}_{4}$. In contrast, dissolution of $\mathrm{Fe}$ (III) minerals by iron reducing bacteria under water-logged conditions leads to release of iron-bound $\mathrm{C}$ as shown in our previous work [1] based on field measurements in Stordalen mire (Abisko, Sweden). But mechanistic understanding of the observed changes in Fe-C associations during thaw is still missing. Thus, the objectives for this project are to 1) elucidate the type of Fe-C interactions in permafrost soil to assess their stability, 2) identify the quality of organic carbon that is preferentially bound to $\mathrm{Fe}$ minerals, and 3) determine the contribution of $\mathrm{Fe}$-associated $\mathrm{C}$ to greenhouse gas formation of $\mathrm{CO}_{2}$ and $\mathrm{CH}_{4}$. To this end, we performed field campaigns in Stordalen mire to obtain soil, pore water and gas samples along a thaw gradient from intact palsa, to partly thawed bog and fully thawed fen. We use bulk measurements (XRF, selective extractions) as well as microscale analysis, including SEM-EDX and nanoSIMS, to characterize the existing $\mathrm{Fe}-\mathrm{C}$ interactions in permafrost soil. Preferential adsorption of soil organic carbon molecules, extracted from different thaw stages, to ferrihydrite will be studied by ultrahigh resolution mass spectrometry. Finally, field measurements of $\mathrm{CO}_{2}$ and $\mathrm{CH}_{4}$ emissions will be compared to laboratory microcosm incubations while monitoring the iron-bound $\mathrm{C}$ content under various temperature and redox cycles. The results of this project will lead to a more comprehensive understanding of the control that iron minerals exert on cycling of organic carbon in thawing permafrost soils.

[1] Patzner et al. (2020), Nature communications 11, 6329. 